\title{
Irrigation during concomitant bipolar ablation: does it matter?
}

\author{
A Bogachev-Prokophiev", S Zheleznev, A Pivkin, S Lavinyukov, I Ivanov, V Nazarov, A Karaskov \\ From 23rd World Congress of the World Society of Cardio-Thoracic Surgeons \\ Split, Croatia. 12-15 September 2013
}

\section{Background}

Use of irrigation catheters increases the power supply energy to create transmural injury [Jais P., Shah D.C., Haissaguerre M. et al., 2000]. However, these data are based on the catheter procedures and concomitant monopolar endocardial ablation [Deneke T., Khargi K. et al., 2007]. The benefits of using irrigation during bipolar concomitant ablation has no reflection in the literature.

\section{Methods}

from 2007 to 2012, 407 patients (mean age $58.2 \pm 10.4$ years) underwent valve or coronary procedure and concomitant bipolar RF ablation for atrial fibrillation (AF). In $152(37,3 \%)$ patients was used irrigated bipolar clamp Medtronic CardioBlate (IB group) and dry bipolar clamp AtriCure Isolator Synergy (DB group) in 255 (62,7\%) cases. Most of the patients in both groups had a long standing persistent AF. There were no significant differences between groups. The follow-up data was analyzed for $36,3 \pm 14,6$ months. Rhythm disturbances evaluated by 24 hours Holter.

\section{Results}

No significant differences in ablation time and aortic cross-clamping: $25.2 \mathrm{~min}$ in BI group and $27.6 \mathrm{~min}$ in BD group ( $\mathrm{p}=0.271$ ); $82.7 \mathrm{~min}$ in BI group and $78.3 \mathrm{~min}$ in BD group ( $\mathrm{p}=0.163)$. There was no difference in hospital mortality between the groups. Specific ablation complication (pulmonary vein perforation) occurred in 1 patient in each group: $0.66 \%$ (BI group) and $0.39 \%$ (BD group) ( $\mathrm{p}=$ 0.576). At latest follow up freedom from $\mathrm{AF}$ was $81.3 \%$ in the BI group and $84.7 \%$ in the BD group ( $\mathrm{p}=0.121)$. Atrial flutter occurred in 5.9\% (BI group) and in 1.9\% (BD group)

\footnotetext{
* Correspondence: bogachev.prokophiev@gmail.com

State Research Institute Blood Circulation Pathology, Novosibirsk, Russian Federation
}

(c) 2013 Bogachev-Prokophiev et al; licensee BioMed Central Ltd. This is an Open Access article distributed under the terms of the Creative Commons Attribution License (http://creativecommons.org/licenses/by/2.0), which permits unrestricted use, distribution, and reproduction in any medium, provided the original work is properly cited. $(\mathrm{p}=0.047)$. All patients with atrial flutter were underwent catheter ablation.

\section{Conclusions}

Comparative analysis revealed no any benefits of using irrigation during concomitant bipolar ablation.

Published: 11 September 2013

doi:10.1186/1749-8090-8-S1-055

Cite this article as: Bogachev-Prokophiev et al.: Irrigation during

concomitant bipolar ablation: does it matter? Journal of Cardiothoracic Surgery 2013 8(Suppl 1):055. and take full advantage of:

- Convenient online submission

- Thorough peer review

- No space constraints or color figure charges

- Immediate publication on acceptance

- Inclusion in PubMed, CAS, Scopus and Google Scholar

- Research which is freely available for redistribution 